\title{
Article \\ Self-Referenced Optical Fiber Sensor Based on LSPR Generated by Gold and Silver Nanoparticles Embedded in Layer-by-Layer Nanostructured Coatings ${ }^{\dagger}$
}

\author{
María Elena Martínez-Hernández ${ }^{1, * \mathbb{D}}$, Xabier Sandúa ${ }^{2,3} \mathbb{D}$, Pedro J. Rivero ${ }^{2,3}$, Javier Goicoechea ${ }^{1,4} \mathbb{D}$ \\ and Francisco J. Arregui ${ }^{1,4}$ (D)
}

1 Department of Electrical, Electronic and Communication Engineering, Campus Arrosadía, Public University of Navarre (UPNA), 31006 Pamplona, Spain; javier.goico@unavarra.es (J.G.); parregui@unavarra.es (F.J.A.)

2 Institute for Advanced Materials and Mathematics (INAMAT2), Campus Arrosadía, Public University of Navarre (UPNA), 31006 Pamplona, Spain; xabier.sandua@unavarra.es (X.S.); pedrojose.rivero@unavarra.es (P.J.R.)

3 Engineering Department, Campus de Arrosadía, Public University of Navarre (UPNA), 31006 Pamplona, Spain

4 Institute of Smart Cities (ISC), Campus de Arrosadía, Public University of Navarre (UPNA), 31006 Pamplona, Spain

* Correspondence: mariaelena.martinez@unavarra.es

+ This manuscript is extension version of the conference paper: Martínez-Hernández, M.E.; Sandua, X.; Rivero, P.; Goicoechea, J.; Arregui, F. An optical fiber sensor for $\mathrm{Hg}^{2+}$ detection based on the LSPR of silver and gold nanoparticles embedded in a polymeric matrix as an effective sensing material. In Proceedings of the 1st International Electronic Conference on Chemical Sensors and Analytical Chemistry (CSAC2021), 1-15 July 2021.

Citation: Martínez-Hernández, M.E.; Sandúa, X.; Rivero, P.J.; Goicoechea,

J.; Arregui, F.J. Self-Referenced

Optical Fiber Sensor Based on LSPR Generated by Gold and Silver Nanoparticles Embedded in Layer-by-Layer Nanostructured Coatings. Chemosensors 2022, 10, 77. https://doi.org/10.3390/

chemosensors10020077

Academic Editor: Nicole Jaffrezic-Renault

Received: 12 November 2021

Accepted: 7 February 2022

Published: 13 February 2022

Publisher's Note: MDPI stays neutral with regard to jurisdictional claims in published maps and institutional affiliations.

Copyright: () 2022 by the authors. Licensee MDPI, Basel, Switzerland. This article is an open access article distributed under the terms and conditions of the Creative Commons Attribution (CC BY) license (https:// creativecommons.org/licenses/by/ $4.0 /)$.

\begin{abstract}
In this work, an optical fiber sensor based on the localized surface plasmon resonance (LSPR) phenomenon has been designed for the detection of two different chemical species (mercury and hydrogen peroxide) by using Layer-by-Layer Embedding (LbL-E) as a nanofabrication technique. In the first step, silver nanoparticles (AgNPs) and gold nanoparticles (AuNPs) have been synthesized by using a chemical protocol as a function of the strict control of three main parameters, which were polyelectrolyte concentration, a loading agent, and a reducing agent. In the second step, their incorporation into nanometric thin films have been demonstrated as a function of the number of bilayers, which shows two well-located absorption peaks associated to their LSPR in the visible region at $420 \mathrm{~nm}$ (AgNPs) and $530 \mathrm{~nm}$ (AuNPs). Finally, both plasmonic peaks provide a stable real-time reference measurement, which can be extracted from the spectral response of the optical fiber sensor, which shows a specific sensing mechanism as a function of the analyte of study.
\end{abstract}

Keywords: fiber optic sensor; gold nanoparticles; silver nanoparticles; localized surface plasmon resonance; Layer-by-Layer Embedding; mercury; hydrogen peroxide

\section{Introduction}

Mercury presents a risk in the pollution of water bodies, affecting human health and the ecosystem. The presence of this type of heavy metal is associated with serious problems, such as lung or nervous system damage, heart diseases, or even neurological and psychological symptoms [1]. Levels of mercury in waste water have to be taken into account, too, in order to take vigorous control of waste management, environmental analysis, toxicology, water safety, and water quality [2]. In order to deal with this toxic compound, several detection methods have been developed, including electrochemical sensors [3-5], colorimetric sensors [6-8], and optical sensors [9-11].

Hydrogen peroxide $\left(\mathrm{H}_{2} \mathrm{O}_{2}\right)$ is also a harmful and toxic substance, which affects psychological, pathological, and environmental fields [12]. It is considered to be a source of 
central nervous system diseases in human bodies [13]. This type of reactive oxygen species (ROS) is produced in food and in biological, chemical, or even in pharmaceutical industrial processes [14]. In addition, $\mathrm{H}_{2} \mathrm{O}_{2}$ has a greater concentration in air and water, which is the main reason to develop new measurement strategies in these media [15]. Similar to mercury detection, several $\mathrm{H}_{2} \mathrm{O}_{2}$ detection methods have been developed, including electrochemical sensors [16-18], colorimetric sensors [19-21] or even optical sensors [22-24]. According to this, this work is focused on optical fiber sensing technology, which has been in a rigorous, continuous growth during the last few decades [25]. Optical fiber sensors offer exclusive features, such as a passive nature, electromagnetic immunity, and chemical stability [26]. In addition, the combination of optical fiber sensing and nanotechnology is an emerging field in the scientific community [27]. One of the research areas of interest is the immobilization of metal nanoparticles in thin films as a result of the optical phenomenon known as localized surface plasmon resonance (LSPR). It is well-known that LSPR is an optical effect which is generated as a result of the interaction between the incident light and the electrons in the conduction band of the metal nanoparticles [28]. Multiple parameters, such as interparticle distance, the dielectric properties of the surrounding polymeric medium, as well as nanoparticle size and shape, have to be considered for an efficient plasmonic effect [29]. As a representative example for mercury detection, gold nanoparticles have been used for the detection of this heavy metal as a result of the formation of an amalgam [30]. More specifically, the interaction Au-Hg makes the chemical modification of the surface nanoparticles possible, which shows an alteration in the resultant size and shape of the nanoparticles [9]. This issue enables a maximum absorbance wavelength shift of the nanoparticles' longitudinal plasmon mode, which is a reliable sensing signal in the optical fiber device [31]. However, previous works have demonstrated that the sensing phenomenon of $\mathrm{H}_{2} \mathrm{O}_{2}$ is based on an intensity absorbance change related to silver nanoparticles (AgNPs) instead of a blue shift of the plasmonic peak. In this case, the sensing mechanism is associated with the chemical reaction between $\mathrm{AgNPs}$ and $\mathrm{H}_{2} \mathrm{O}_{2}$ in which the metal nanoparticles are oxidized towards silver ions $\left(\mathrm{Ag}^{+}\right)$, and, consequently, a gradual reduction in the plasmonic LSPR peak of AgNPs is obtained. However, an interesting result is that $\mathrm{H}_{2} \mathrm{O}_{2}$ has shown an influence on the morphological and chemical state of AuNPs, which maintain an LSPR peak centered at $530 \mathrm{~nm}$ [32].

In this work, the employed nanofabrication bottom-up process is the Layer-by-Layer $(\mathrm{LbL})$ nanoassembly technique. This deposition method makes the fabrication of ultra-thin films (sensitive region) on optical fiber cores possible by using oppositely charged polyelectrolytes, which act as effective capping agents of the metallic nanoparticles [33-35]. In addition, this nanofabrication technique makes it possible to obtain thin films with a good control of the resultant thickness in the nanometric range, which acts as a function of operational parameters, such as $\mathrm{pH}$, ionic strength, or the number of bilayers deposited $[36,37]$. The novelty of this work is the possibility of introducing two different metallic nanoparticles, such as AgNPs and AuNPs, into LbL films, making it possible to obtain two different LSPR sensing signals for the detection of both mercury [38] and hydrogen peroxide, respectively, in an aqueous medium. Firstly, an initial study is performed with glass slides in order to optimize the nanofabrication technique, and secondly, the sensing coating is implemented onto the optical fiber. Finally, the experimental results corroborate the possibility of the stable detection of two different parameters with a different sensing mechanism, which is based on the wavelength displacement of the LSPR associated to the strong affinity of the mercury towards AuNPs or to the reduction in the LSPR associated with the oxidation process of the AgNPs due to the action of hydrogen peroxide.

\section{Experimental Section}

\subsection{Materials}

The polyelectrolytes used for the fabrication of the multilayer structure are poly(allylamine hydrochloride) (PAH) $\left(\mathrm{M}_{\mathrm{W}} \sim 17,500\right)$ (polycation) and poly(acrylic acid) (PAA) $\left(\mathrm{M}_{\mathrm{W}} \sim 250,000\right)$ $35 \mathrm{wt} \%$ solution in water (polyanion). The synthesis of both metallic nanoparticles 
was achieved by using a source of metal ions, which were gold (III) chloride trihydrate $\left(\mathrm{HAuCl}_{4} \cdot 3 \mathrm{H}_{2} \mathrm{O}\right)$ and silver nitrate $\left(\mathrm{AgNO}_{3}\right)$, respectively. Dimethylamine borane complex (DMAB) was used for the reduction in the metal ions in AgNPs and AuNPs. The mercury detection substance was obtained from mercury (II) chloride $\left(\mathrm{HgCl}_{2}\right)$, and an aqueous solution of $30 \mathrm{wt} \%$ of $\mathrm{H}_{2} \mathrm{O}_{2}$ was used in order to obtain the hydrogen peroxide samples. All the chemical reagents were provided by Sigma-Aldrich for any further purification. Finally, ultrapure water with a resistivity of $18.2 \mathrm{M} \Omega \cdot \mathrm{cm}$ was employed as deionized water.

\subsection{Synthesis of the Metallic Nanoparticles}

For the synthesis of AuNPs, aqueous solutions of $\mathrm{HAuCl}_{4} \cdot 3 \mathrm{H}_{2} \mathrm{O}(20 \mathrm{~mL}, 5 \mathrm{mM})$ and PAA $(120 \mathrm{~mL}, 10 \mathrm{mM})$, which act as capping agents, were mixed and stirred for a period of $2 \mathrm{~h}$. After that, an aqueous solution of the reducing agent DMAB $(5 \mathrm{~mL}, 100 \mathrm{mM})$ was added to the previous solution, and the mixture was stirred for $24 \mathrm{~h}$ at room temperature. Finally, a color change from yellow to purple-violet was obtained, indicating the complete synthesis of the AuNPs. The combination of PAA and AuNPs is denoted as PAA-AgNPs.

For the synthesis of AgNPs, firstly, aqueous solutions of $\mathrm{AgNO}_{3}(20 \mathrm{~mL}, 10 \mathrm{mM})$ and PAH (120 mL, $10 \mathrm{mM})$, which act as capping agents, were mixed and stirred for a period of $2 \mathrm{~h}$. After that, an aqueous solution of the reducing agent DMAB $(5 \mathrm{~mL}, 100 \mathrm{mM})$ was added to the initial solution, and the mixture was stirred for $24 \mathrm{~h}$ at room temperature. Finally, a color change from transparent to orange was obtained, indicating the complete synthesis of the AgNPs. The combination of PAH and AgNPs is denoted as PAH-AgNPs. Finally, the aqueous solutions of both metallic nanoparticles were adjusted at a $\mathrm{pH}$ of 7.0.

\subsection{Fabrication of the Layer-by-Layer Films}

The Layer-by-Layer nanoassembly technique was used for the fabrication of the multilayer structure. In this work, the presence of PAH and PAA were used as the positive and negative charged polyelectrolytes for the build-up of the polyelectrolyte structure film. In addition, as it has been demonstrated in the previous section, these charged structures also played a key role in stabilizing the synthesized metallic nanoparticles. The nanofabrication process was based on the sequential exposition of the substrate (glass slide and optical fiber core) to the polycationic solution PAH-capped AgNPs (PAH-AgNPs) and to the polyanion PAA-capped AuNPs (PAA-AuNPs) with an immersion time of $5 \mathrm{~min}$. Rinsing for $1 \mathrm{~min}$ in deionized water was performed for the two polyelectrolytes baths, and drying for $30 \mathrm{~s}$ was performed after each rinsing step. The combination of a cationic monolayer with an anionic monolayer is called a bilayer. The LbL process was carried out using a 3-axis cartesian robot from Nadetech Innovations. Finally, an important aspect to remark is that no atmospheric oxidation of the LbL films was observed using this experimental process, which shows the long-term stability of the resultant films.

\subsection{Characterization Techniques}

UV-visible spectroscopy (UV-Vis) was used to characterize the optical properties of the metallic nanoparticles and of the resultant LbL films. The measurements were conducted with a Jasco V-630 spectrophotometer.

Atomic force microscopy (AFM) was used to characterize the thickness and the surface morphology of the LbL coatings. The samples were scanned by using a Veeco Innova AFM in tapping mode.

\subsection{Optical Fiber Detection Setup}

A multimode optical fiber with a $200 \mu \mathrm{m}$ core diameter with polymeric cladding, 0.39 NA (THORLABS FT 200EMT) was used for the fabrication of the optical fiber sensor. First, it was necessary to remove the acrylate cladding of a segment of approximately $2 \mathrm{~cm}$ of the optical fiber; for this, a few drops of dry acetone and a blade were used, which exposed the bare optical fiber core in its entire cylindrical section. This optical fiber segment was immersed for $5 \mathrm{~min}$ in piranha solution to eliminate the acetone that could remain. 
Temporary SMA connectors were used in the ends of the optical fiber, thus exciting a sensor from one of the connectors with a halogen white source, and the other end collected the optical response with a CCD spectrometer (HR4000-UV Ocean Optics). Finally, a schematic representation of the deposition process as well as the optical fiber setup is presented in Figure 1.
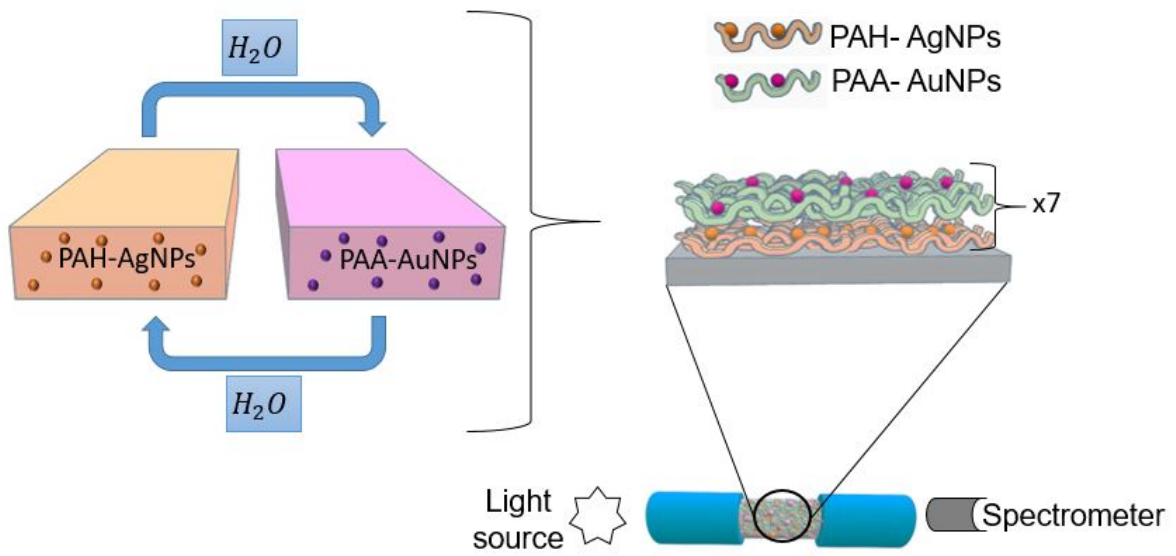

Figure 1. Schematic representation for the fabrication of the LbL nanostructured thin film (sensitive region) and the optical setup for analyte detection.

\subsection{Analyte Samples Preparation}

Mercury samples were prepared by using mercury (II) chloride $\left(\mathrm{HgCl}_{2}\right)$. Every concentration of mercury was prepared with phosphate buffer (PB) solution for achieving a constant $\mathrm{pH}$ of 7.6. The $\mathrm{Hg}$ concentrations were 50, 25, 1, and $0.1 \mathrm{ppm}$. An important aspect is that, for each measurement, the fiber optical sensor was immersed in PB + DMAB buffer solution with the aim of obtaining a stable baseline for further mercury detection.

For the preparation of the hydrogen peroxide samples, phosphate buffer (PB) was used as solvent. $\mathrm{H}_{2} \mathrm{O}_{2}$ concentrations of 10,5 , and $1 \mathrm{ppb}$ were tested. For each measurement, the fiber optic sensor was introduced into the PB in the same way that it was conducted with $\mathrm{Hg}$.

\section{Results and Discussion}

Prior to the deposition onto optical fiber, an exhaustive initial analysis about the dispersion of the nanoparticles in the solution and their further immobilization in LbL multilayer structures had been performed on glass slides.

\subsection{Synthesis of the Metallic Nanoparticles and Their Incorporation into LbL Films}

As has been commented in the experimental section, both metallic nanoparticles have been synthesized by using different charged capping agents. In the case of AgNPs, a positive polyelectrolyte (PAH) has been used for obtaining PAH-AgNPs, whereas in the case of AuNPs, a negative polyelectrolyte (PAA) has been used for obtaining PAA-AuNPs. Figure 2 shows the corresponding plasmonic peaks at a well-separated wavelength position related to AgNPs and AuNPs. More specifically, the LSPR of the PAH-AgNPs is centered at $400 \mathrm{~nm}$, whereas the LSPR of PAA-AuNPs is centered at $530 \mathrm{~nm}$. The locations of these LSPR bands indicate the synthesis of metal nanoparticles with a mostly spherical shape and nanometric size $[39,40]$. 


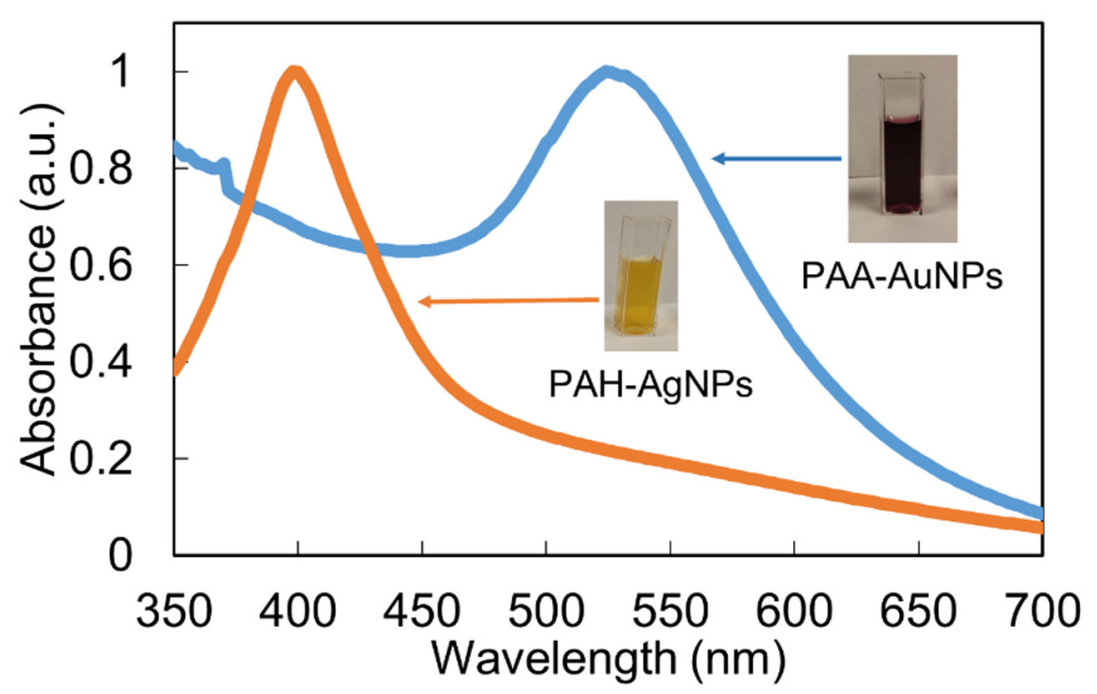

Figure 2. UV-Vis spectra of both aqueous dispersion solutions for PAH-AgNPs (yellow) and PAAAuNPs (purple).

Once the synthesis of the well-dispersed nanoparticles in the aqueous solution has been demonstrated, the next step is the immobilization of them in thin films by using the Layer-by-Layer nanoassembly technique. Figure 3 shows the UV-Vis spectra of the LbL-E films deposited onto glass slides for a thickness variation of 10 to 30 bilayers. It can be clearly appreciated that the sample composed of 10 bilayers has shown a clear predominance of the LSPR peak related to AgNPs (plasmonic peak centered at $420 \mathrm{~nm}$ ), whereas the LSPR peak associated with the AuNPs has not yet been identified. However, when the thickness coating is gradually increased up to 30 bilayers, both LSPR peaks can be clearly observed at $420 \mathrm{~nm}$ for AgNPs and $530 \mathrm{~nm}$ for AuNPs. Another aspect to remark is that a protuberance around $650 \mathrm{~nm}$ can also be observed, which is associated with an agglomeration of the metal nanoparticles in the multilayer structure, although this protuberance is smoother as the thickness coatings are gradually increased. This aspect can be appreciated in Figure 4, where the 3D AFM image indicates that nanoparticles of different sizes have been incorporated into the LBL films (see Figure 4a), and the average thickness coating is gradually increased up to an approximate value of $100 \mathrm{~nm}$, as can be observed in the bilayers sample (Figure $4 \mathrm{~b}$ ). AFM images reveal the nano-roughness of the LbL film (9 $\mathrm{nm} \mathrm{rms),} \mathrm{which} \mathrm{is} \mathrm{consistent} \mathrm{with} \mathrm{previous} \mathrm{works} \mathrm{[41,42]} \mathrm{where} \mathrm{PAH-}$ PAA LbL membranes show a nanoporosity that allows an effective interaction between the nanoparticles and the sensing analytes. Finally, broader LSPR absorption bands are obtained in the resultant Layer-by-Layer Embedding film in comparison with the colloidal dispersions (see Figure 2) due to the agglomeration of the metallic nanoparticles in the nanostructured coating [40-42]. 


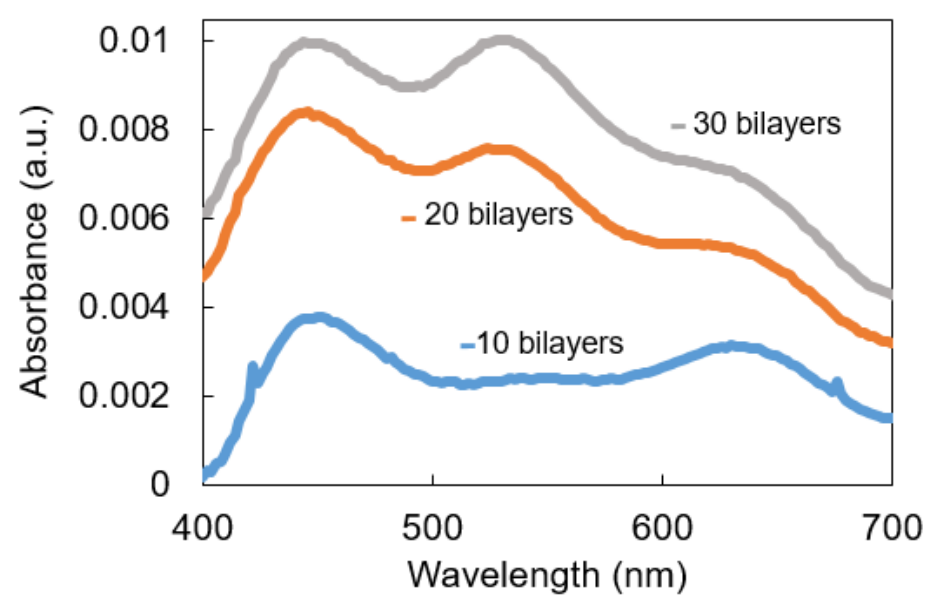

Figure 3. UV-Vis spectra of the LbL coatings based on PAH-AgNPs and PAA-AuNPs deposited onto glass slides as a function of the thickness coating (10, 20, and 30 bilayers).

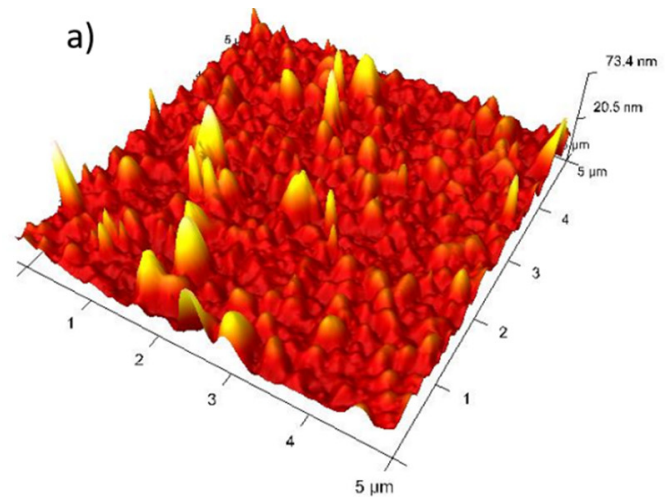

b)

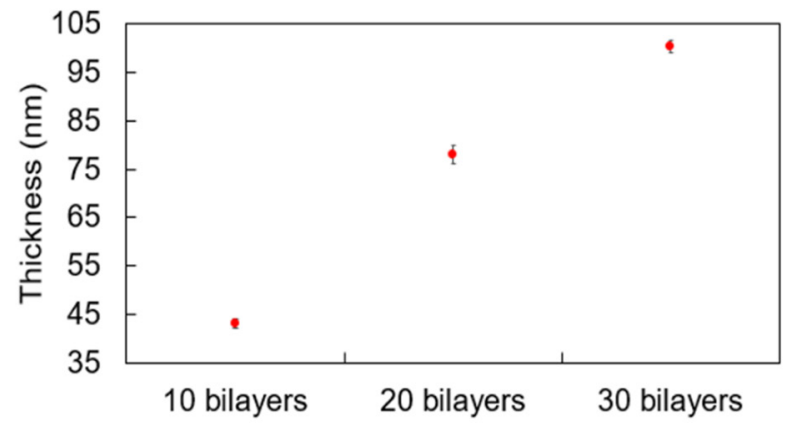

Figure 4. (a) 3D Atomic Force Microscopy image for the glass substrate sample corresponding to 30 bilayers and $\mathrm{pH}$ 7. (b) Thickness increment as a function of the number of bilayers.

\subsection{Optical Fiber Setup Fabrication}

Once the presence of both LSPR peaks on glass slides has been demonstrated, the next step is based on the fabrication of the sensitive region, which is deposited onto the optical fiber core by using the same multilayer structure composed of both AgNPs and AuNPs, as can be observed in the UV-Vis spectra of Figure 5. An interesting result is that, for only a final thickness coating of seven bilayers, it is possible to clearly appreciate both LSPR absorption bands at $420 \mathrm{~nm}$ (AgNPs) and $540 \mathrm{~nm}$ (AuNPs). More specifically, Figure 5a presents the UV-Vis spectra evolution from one up to seven bilayers, which are the last of the sensitive regions for analyte detection, and Figure $5 b$ shows the UV-Vis spectrum for the sample of seven bilayers and the wavelength separation of both LSPR absorption bands. 
a)

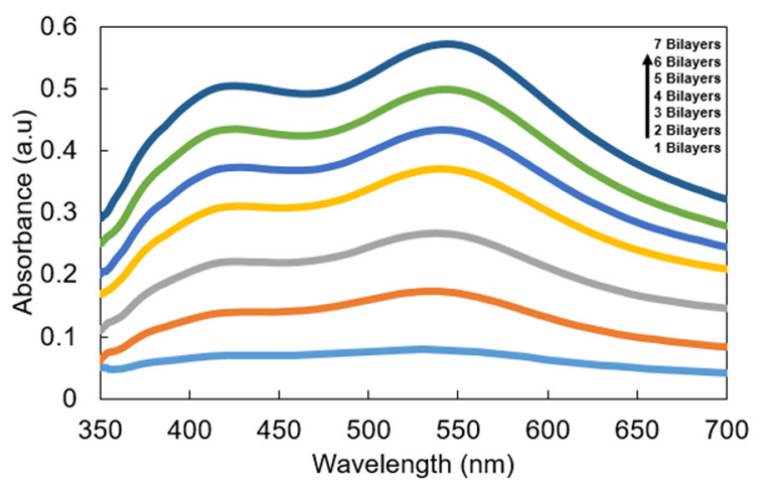

b)

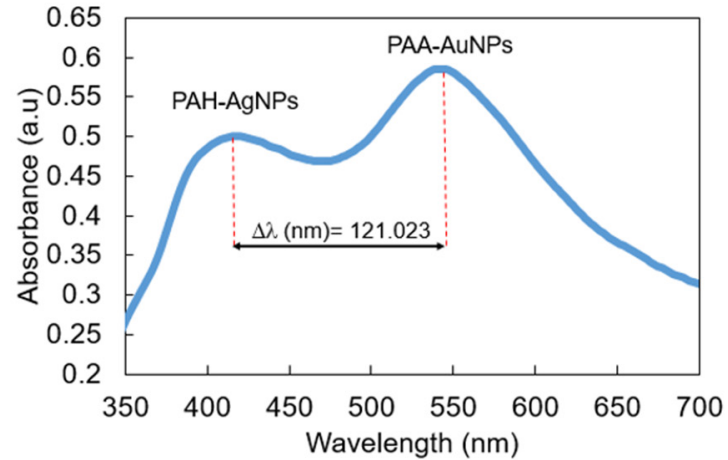

Figure 5. (a) UV-Vis spectra of the LbL coatings as a function of the number of bilayers. (b) Final aspect of the UV-Vis spectrum related to (PAH-AgNPs/PAA-AuNPs) 7 with the corresponding wavelength separation of both LSPR absorption bands.

\subsection{Mercury Ions Detection}

In this work, optical fiber sensors have been fabricated using the same sensitive coating (seven bilayers of PAH-AgNPs and PAA-AuNPs), and each one has been used to detect a specific mercury concentration. All of the sensors have shown a settling time of nearly $2000 \mathrm{~s}$ from $10 \%$ to $90 \%$; such long reaction times may be due to the lower diffusivity in the LbL polyelectrolyte membrane of heavy ions such as mercury. For each concentration, a fresh sensor has been used, so the wavelength response can be completely attributed to the mercury amalgamation with the AuNPs. The LSPR absorption band related to AuNPs has shown a blue shift, which is notorious for higher mercury concentrations. Figure 6 shows the absolute value of the wavelength shift of each sensor, and it can be observed that a gradual increase in the resultant wavelength shift has been obtained from $4.32 \mathrm{~nm}$ (0.1 ppm), $17.70 \mathrm{~nm}(1 \mathrm{ppm}), 21.61 \mathrm{~nm}(25 \mathrm{ppm})$, and $22.24 \mathrm{~nm}(50 \mathrm{ppm})$.

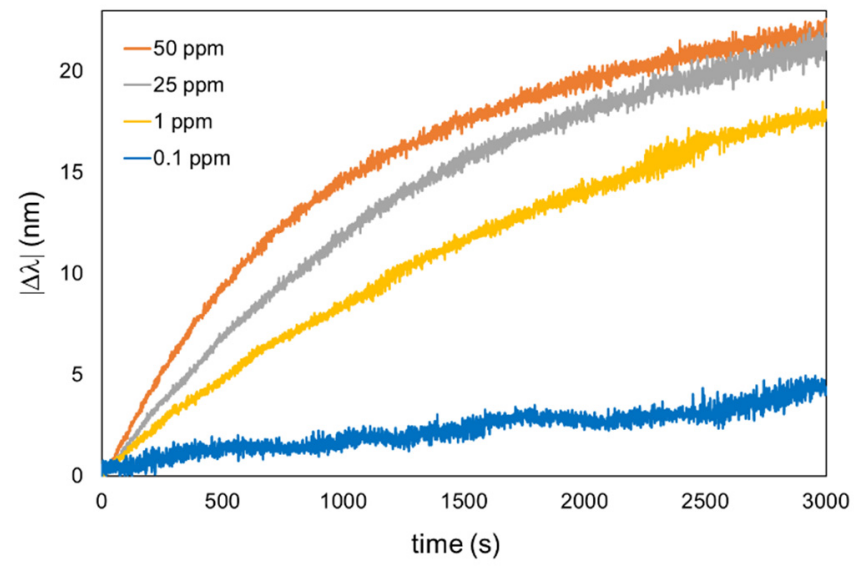

Figure 6. Dynamic response of the optical fiber sensors of different $\mathrm{Hg}$ concentrations, ranging from $50 \mathrm{ppm}$ to $0.1 \mathrm{ppm}$.

The UV-Vis transient response of one sensor is presented in Figure 7 in order to have a better appreciation of the wavelength shift related to the LSPR-AuNPs. The AgNP LSPR maxima shows a good wavelength stability with a variation of only $3.1 \mathrm{~nm}$, compared with the $20.2 \mathrm{~nm}$ of the AuNP LSPR peak (Figure 7c). The Limit of Detection (LOD) of this sensor can be assumed to be $0.1 \mathrm{ppm}$, since no significant AuNP LSPR shift has been observed for lower $\mathrm{Hg}^{2+}$ concentrations. 
a)

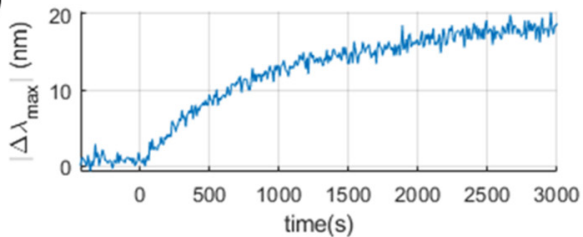

b)

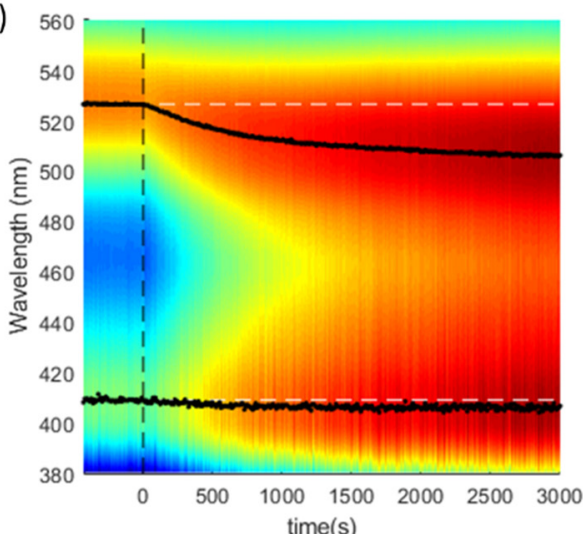

c)

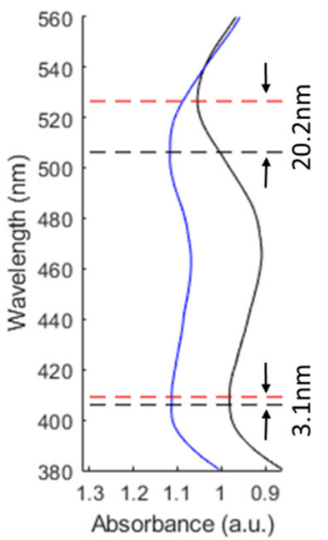

Figure 7. Transient response of a (PAH-AgNPs/PAA-AuNPs $)_{7}$ optical fiber sensor for $\left[\mathrm{Hg}^{2+}\right]=1 \mathrm{ppm}$ : (a) Variation of the AuNPs LSPR with maximum respect to the AgNPs LSPR reference. (b) Heatmap of the evolution of the UV-Vis spectra during the experiment. The initial wavelengths of AuNP and AgNP LSPR peaks are marked wih white dashed lines. (c) Initial and final spectral response of the optical fiber sensor.

The specificity of heavy metal detection is a very important factor for practical applications. In this work, the cross sensitivity against different metal ions in order to corroborate the selectivity of the optical fiber sensor has been also evaluated. According to this, the same sensitive region has been exposed to the same concentration (50 ppm) of the different metal ions $\left(\mathrm{Zn}^{2+}, \mathrm{Cd}^{2+}, \mathrm{Pb}^{2+}, \mathrm{Ni}^{2+}\right.$ and $\left.\mathrm{Fe}^{2+}\right)$ for a fixed period of $30 \mathrm{~min}$. It is important to remark that all the solutions were prepared using the same protocol as was used in the previous mercury tests $(\mathrm{PB}+\mathrm{DMAB}, \mathrm{pH} 7.6)$. The experimental results (see Figure 8) indicate that the wavelength shift of $\mathrm{Hg}^{2+}$ is much larger than that of the other ions. More specifically, the LSPR-AuNPs present a higher affinity for mercury ions with a wavelength shift of $13.88 \mathrm{~nm}$, whereas $\mathrm{Fe}^{2+}$ was the second heavy metal with a higher response but with only a wavelength shift of $1.17 \mathrm{~nm}$. These results demonstrate the high selectivity to mercury of the optical fiber sensor. These values are in concordance with what is reported in the bibliography [43]. 


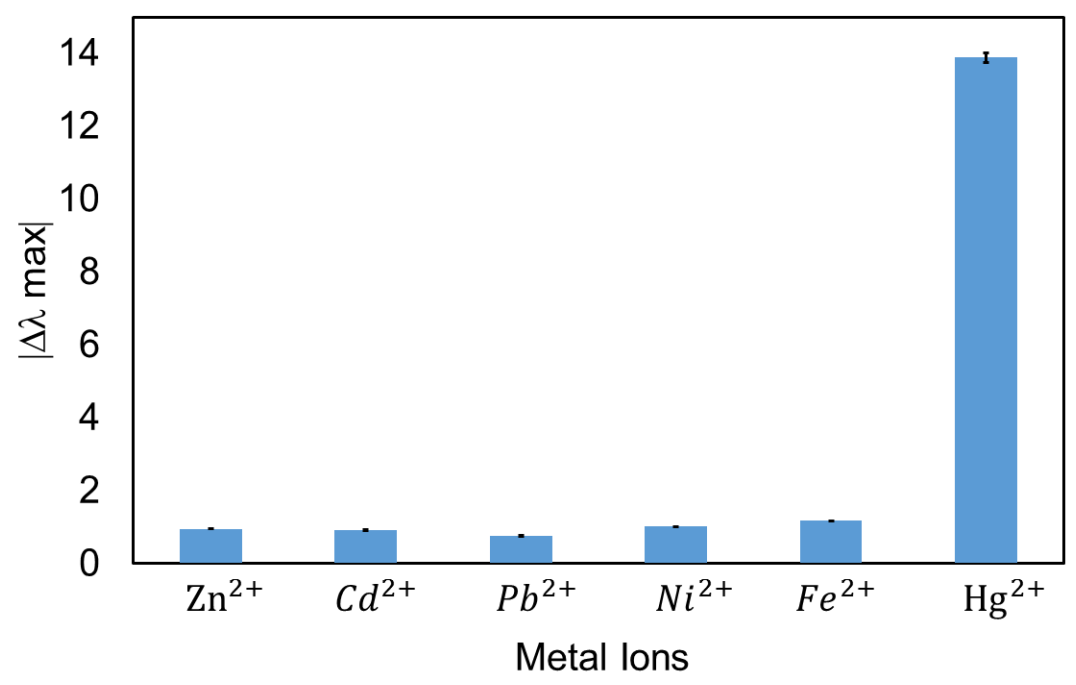

Figure 8. Selectivity analysis against the most common heavy metals showing the wavelength shift of the LSPR (AuNPs) optical fiber sensors in different ion solutions with a concentration of $50 \mathrm{ppm}$ and a response time of $30 \mathrm{~min}$.

\section{4. $\mathrm{H}_{2} \mathrm{O}_{2}$ Detection}

In the previous section, the experimental results have clearly shown a specific sensitivity to the LSPR band associated with the AuNPs, whereas the LSPR band of the AgNPs remained unaltered in wavelength (reference signal), which can be seen in Figure 9a. In this section, a change in the plasmonic behavior of the AgNPs when the sensitive region is exposed to hydrogen peroxide is presented. Previous works have demonstrated that this analyte induces a degradation in the LSPR-AgNPs due to the corresponding oxidation of silver nanoparticles to silver ions $\left(\mathrm{Ag}^{+}\right)$[32]. More specifically, the degradation of the resultant silver nanoparticles, which is induced by the catalytic decomposition of hydrogen peroxide, causes a considerable change in the absorbance strength of the LSPR absorption band depending on the $\mathrm{H}_{2} \mathrm{O}_{2}$ concentration, making a quantitative determination of this sensing analyte possible $[44,45]$. All sensors showed a stable optical signal in all aqueous buffered media, and their optical responses can be attributed entirely to the hydrogen peroxide concentration. According to this, a new optical fiber sensor has been fabricated by using the same protocol, although it was used for hydrogen peroxide detection in this case. The optical fiber has been immersed in the buffer PB solution for $1 \mathrm{~h}$ to have a stable baseline for hydrogen peroxide. Subsequently, the sensitive region of the optical fiber sensor film has been immersed in an initial hydrogen peroxide concentration of $10 \mathrm{ppb}$. The experimental results are presented in Figure 9b, where it can be clearly observed that the LSPR-AgNPs have shown an absorbance reduction of 0.16 a.u., whereas the LPSRAuNPs have shown a significatively more stable behavior, making it possible to use it as a reference signal.

Figure 10 shows the transient response of a (PAH-AgNPs/PAA-AuNPs) $)_{7}$ optical fiber sensor when exposed to a concentration of $\mathrm{H}_{2} \mathrm{O}_{2}$ of $3 \mathrm{ppb}$. The sensitivity of the optical fiber sensor to $\mathrm{H}_{2} \mathrm{O}_{2}$ analyte is higher in comparison with that of previous works [31], in which the sensing range is in the order of the ppb. An increase in the absorbance reduction related to the LSPR peak is observed when the $\mathrm{H}_{2} \mathrm{O}_{2}$ concentration is gradually increased, which is in concordance with the literature because a major $\mathrm{H}_{2} \mathrm{O}_{2}$ concentration in the buffer makes a higher oxidation rate of the silver nanoparticles immobilized in the multilayer LbL structure possible. 
a)

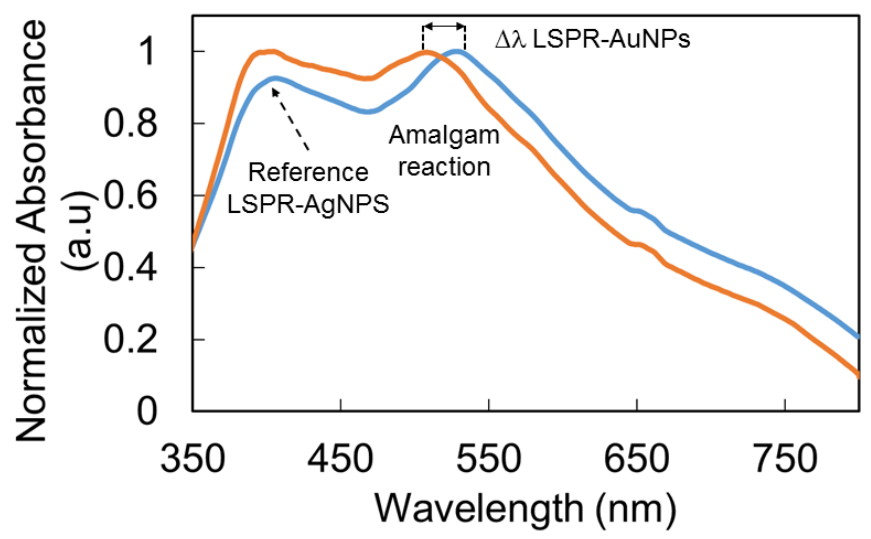

b)

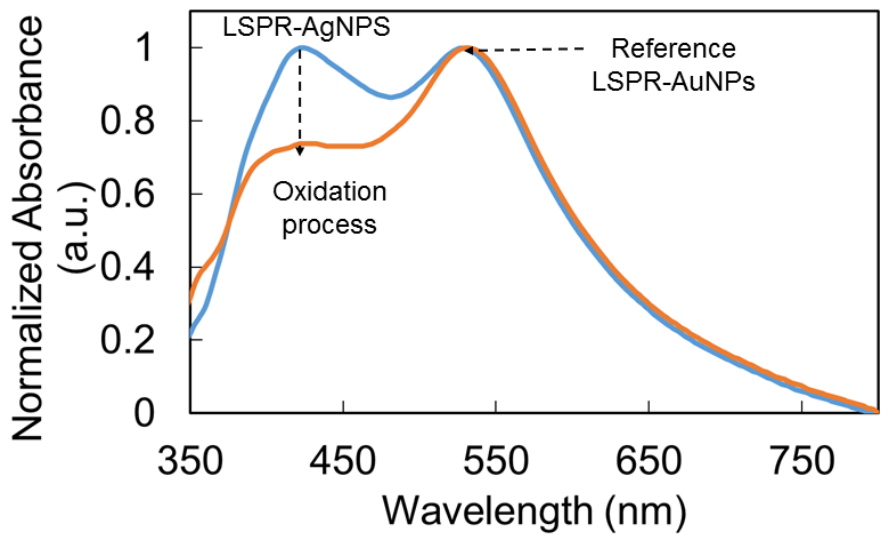

Figure 9. Comparative graph based on the sensing mechanism of the dual LSPR optical fiber sensor for mercury detection (a) and hydrogen peroxide detection (b), being one of the LSPR sensing signals unaltared in wavelenght position. The blue plot corresponds to the immersion in buffer phosphate and the orange plot corresponds to a concentration of $50 \mathrm{ppm}$ for $\mathrm{Hg}$ and $10 \mathrm{ppb}$ for $\mathrm{H}_{2} \mathrm{O}_{2}$, respectively.

a)

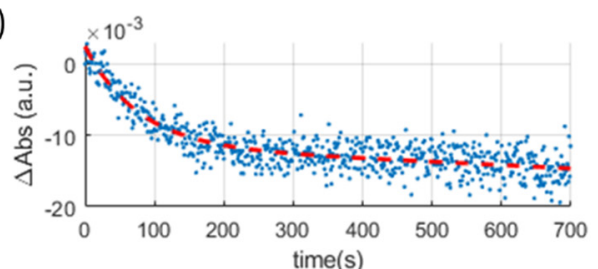

b)

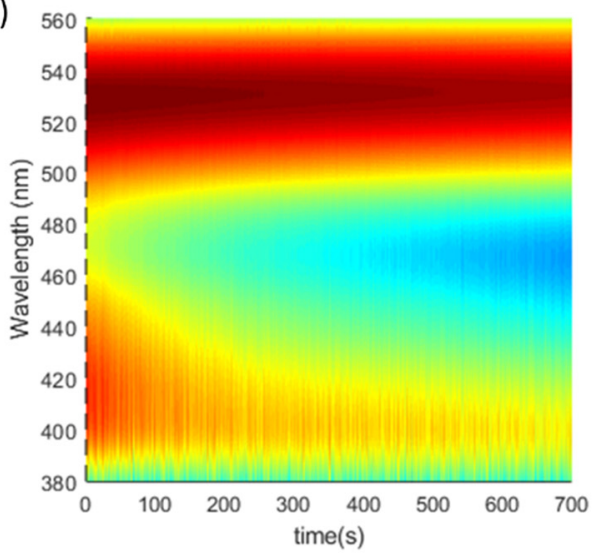

c)

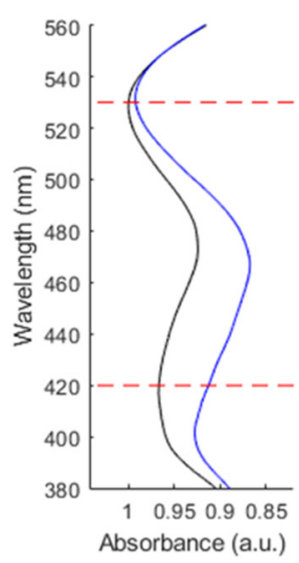

Figure 10. Transient response of a (PAH-AgNPs/PAA-AuNPs $)_{7}$ optical fiber sensor for $\left[\mathrm{H}_{2} \mathrm{O}_{2}\right]=3$ ppb: (a) Variation of the absorbance of the AgNPs LSPR with maximum respect to the AuNPs LSPR reference. (b) Heatmap of the evolution of the UV-Vis spectra during the experiment. (c) Initial and final spectral response of the optical fiber sensor.

Finally, the sensitive region has been immersed in five different concentrations $(0.1,1$, 3,5 , and $10 \mathrm{ppb}$ ) in order to appreciate the declining tendency of the absorbance intensity corresponding to the AgNP plasmonic peak (see Figure 10). Figure 11 shows the maximum variation in absorbance $(\Delta \mathrm{Abs})$ for each $\mathrm{f}$ hydrogen peroxide concentration, which shows a good logarithmic fitting. 


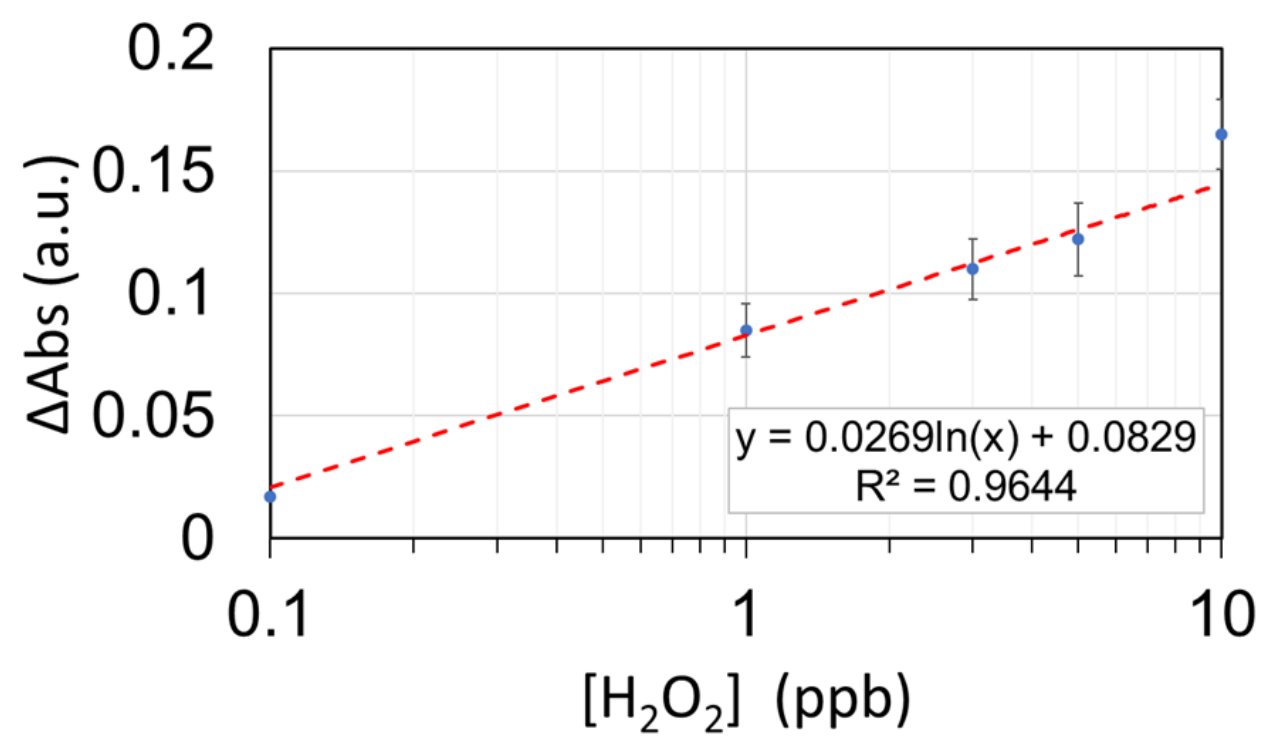

Figure 11. Calibration curve of the (PAH-AgNPs/PAA-AuNPs) $)_{7}$ optical fiber sensor towards $\mathrm{H}_{2} \mathrm{O}_{2}$. The sensor has been tested for $0.1,1,3,5$, and $10 \mathrm{ppb}$.

The sensor's response was registered for the following concentrations: 0.1, 1, 3, 5, and $10 \mathrm{ppb}$. Beyond a $10 \mathrm{ppb}$ concentration, the sensor shows some signs of saturation decreasing its sensitivity significantly. The standard deviation of each measurement was registered and showed a stable behavior, which was around 0.015 a.u. for both the baseline and the measurements. Using the $3 \sigma$ criterion above the baseline, we can determine a theoretical Limit of Detection (LOD) of $0.24 \mathrm{ppb}$ of $\mathrm{H}_{2} \mathrm{O}_{2}$. Therefore, the useful range for this configuration would be from 2.4 to $10 \mathrm{ppb}$ of $\mathrm{H}_{2} \mathrm{O}_{2}$.

\section{Conclusions}

Silver and gold nanoparticles have been successfully embedded into nanostructured thin films by using the Layer-by-Layer technique. The charged polyelectrolytes are used as a versatile tool for the synthesis of silver nanoparticles (PAH-AgNPs) and gold nanoparticles (PAA-AuNPs) into the multilayer structure in the nanometric range (corroborated by AFM analysis). An initial study on glass slides was performed in order to corroborate the presence of both metallic nanoparticles in LbL films with their corresponding optical properties. The next step was to perform further immobilizations in optical fibers for chemical detection. In this sense, two different environmental pollutants $\left(\mathrm{Hg}^{2+}\right.$ and $\mathrm{H}_{2} \mathrm{O}_{2}$ ) have been evaluated as a function of the LSPR response. In both cases, the use of a self-referenced signal provided a robustness in the sensing mechanism, which was different for each analyte of study. In the case of LSPR-AuNPs, this absorption peak has experienced a wavelength shift in the presence of different $\mathrm{Hg}^{2+}$ concentrations, whereas the LSPR-AgNPs have only experienced variations for variable $\mathrm{H}_{2} \mathrm{O}_{2}$ concentrations with a decrease in absorbance magnitude. This study introduces a new multifunctional fiber optic sensor for the detection of $\mathrm{Hg}^{2+}$ and $\mathrm{H}_{2} \mathrm{O}_{2}$ and is a proposal of interest for future environmental applications.

Author Contributions: Conceptualization and Methodology, M.E.M.-H., X.S., P.J.R., J.G. and F.J.A.; Investigation and Validation, M.E.M.-H. and X.S.; Writing-Original Draft Preparation, M.E.M.-H., X.S. and P.J.R.; Writing-Review and Editing, P.J.R., J.G. and F.J.A.; Supervision, P.J.R., J.G. and F.J.A.; Project Administration and Funding Acquisition, F.J.A. All authors have read and agreed to the published version of the manuscript.

Funding: This research was funded by the Spanish Agencia Estatal de Investigación (AEI), grant number PID2019-106070RB-I00.

Institutional Review Board Statement: Not applicable. 
Informed Consent Statement: Not applicable.

Data Availability Statement: Not applicable.

Conflicts of Interest: The authors declare no conflict of interest.

\section{References}

1. Järup, L. Hazards of Heavy Metal Contamination. Br. Med. Bull. 2003, 68, 167-182. [CrossRef]

2. Jia, S.; Bian, C.; Sun, J.; Tong, J.; Xia, S. A Wavelength-Modulated Localized Surface Plasmon Resonance (LSPR) Optical Fiber Sensor for Sensitive Detection of Mercury(II) Ion by Gold Nanoparticles-DNA Conjugates. Biosens. Bioelectron. 2018, $114,15-21$. [CrossRef]

3. Abu-Ali, H.; Nabok, A.; Smith, T.J. Development of Novel and Highly Specific SsDNA-Aptamer-Based Electrochemical Biosensor for Rapid Detection of Mercury (II) and Lead (II) Ions in Water. Chemosensors 2019, 7, 27. [CrossRef]

4. $\quad$ Bansod, B.K.; Kumar, T.; Thakur, R.; Rana, S.; Singh, I. A Review on Various Electrochemical Techniques for Heavy Metal Ions Detection with Different Sensing Platforms. Biosens. Bioelectron. 2017, 94, 443-455. [CrossRef]

5. Deshmukh, M.A.; Celiesiute, R.; Ramanaviciene, A.; Shirsat, M.D.; Ramanavicius, A. EDTA_PANI/SWCNTs Nanocomposite Modified Electrode for Electrochemical Determination of Copper (II), Lead (II) and Mercury (II) Ions. Electrochim. Acta 2018, 259, 930-938. [CrossRef]

6. Zhang, X.; Liu, W.; Li, X.; Zhang, Z.; Shan, D.; Xia, H.; Zhang, S.; Lu, X. Ultrahigh Selective Colorimetric Quantification of Chromium(VI) Ions Based on Gold Amalgam Catalyst Oxidoreductase-like Activity in Water. Anal. Chem. 2018, 90, 14309-14315. [CrossRef]

7. Chen, Z.; Zhang, C.; Gao, Q.; Wang, G.; Tan, L.; Liao, Q. Colorimetric Signal Amplification Assay for Mercury Ions Based on the Catalysis of Gold Amalgam. Anal. Chem. 2015, 87, 10963-10968. [CrossRef]

8. Priyadarshini, E.; Pradhan, N. Gold Nanoparticles as Efficient Sensors in Colorimetric Detection of Toxic Metal Ions: A Review. Sens. Actuators B Chem. 2017, 238, 888-902. [CrossRef]

9. Martínez-Hernández, M.E.; Goicoechea, J.; Arregui, F.J. $\mathrm{Hg}^{2+}$ Optical Fiber Sensor Based on LSPR Generated by Gold Nanoparticles Embedded in LBL Nano-Assembled Coatings. Sensors 2019, 19, 4906. [CrossRef]

10. Cao, J.; Sun, T.; Grattan, K.T.V. Gold Nanorod-Based Localized Surface Plasmon Resonance Biosensors: A Review. Sens. Actuators B Chem. 2014, 195, 332-351. [CrossRef]

11. James, J.Z.; Lucas, D.; Koshland, C.P. Gold Nanoparticle Films as Sensitive and Reusable Elemental Mercury Sensors. Environ. Sci. Technol. 2012, 46, 9557-9562. [CrossRef] [PubMed]

12. Zhao, J.; Yan, Y.; Zhu, L.; Li, X.; Li, G. An Amperometric Biosensor for the Detection of Hydrogen Peroxide Released from Human Breast Cancer Cells. Biosens. Bioelectron. 2013, 41, 815-819. [CrossRef] [PubMed]

13. Luo, Y.; Liu, H.; Rui, Q.; Tian, Y. Detection of Extracellular $\mathrm{H}_{2} \mathrm{O}_{2}$ Released from Human Liver Cancer Cells Based on TiO Nanoneedles with Enhanced Electron Transfer of Cytochrome C. Anal. Chem. 2009, 81, 3035-3041. [CrossRef] [PubMed]

14. Magyar, M.; Rinyu, L.; Janovics, R.; Berki, P.; Hernádi, K.; Hajdu, K.; Szabó, T.; Nagy, L. Real-Time Sensing of Hydrogen Peroxide by Ito/Mwcnt/Horseradish Peroxidase Enzyme Electrode. J. Nanomater. 2016, 2016. [CrossRef]

15. Mao, J.; Jacob, D.J.; Evans, M.J.; Olson, J.R.; Ren, X.; Brune, W.H.; St. Clair, J.M.; Crounse, J.D.; Spencer, K.M.; Beaver, M.R.; et al. Chemistry of Hydrogen Oxide Radicals (HOx) in the Arctic Troposphere in Spring. Atmos. Chem. Phys. 2010, 10, 5823-5838. [CrossRef]

16. Martínez-Huitle, C.A.; Brillas, E. Decontamination of Wastewaters Containing Synthetic Organic Dyes by Electrochemical Methods: A General Review. Appl. Catal. B Environ. 2009, 87, 105-145. [CrossRef]

17. Chen, W.; Cai, S.; Ren, Q.Q.; Wen, W.; Zhao, Y.D. Recent Advances in Electrochemical Sensing for Hydrogen Peroxide: A Review. Analyst 2012, 137, 49-58. [CrossRef]

18. Hrapovic, S.; Liu, Y.; Male, K.B.; Luong, J.H.T. Platinum Nanoparticles and Carbon Nanotubes Interactions with Pt Nanoparticles to Form a Network That Connected Pt Nanoparticles to the Electrode Surface. TEM Nanoparticles on Carbon Nanotubes Whereas Cyclic Volta. Anal. Chem. 2004, 76, 1083-1088. [CrossRef]

19. Erel, O. A New Automated Colorimetric Method for Measuring Total Oxidant Status. Clin. Biochem. 2005, 38, 1103-1111. [CrossRef]

20. Chen, S.; Hai, X.; Chen, X.W.; Wang, J.H. In Situ Growth of Silver Nanoparticles on Graphene Quantum Dots for Ultrasensitive Colorimetric Detection of $\mathrm{H}_{2} \mathrm{O}_{2}$ and Glucose. Anal. Chem. 2014, 86, 6689-6694. [CrossRef]

21. Chen, Y.; Zhong, Q.; Wang, Y.; Yuan, C.; Qin, X.; Xu, Y. Colorimetric Detection of Hydrogen Peroxide and Glucose by Exploiting the Peroxidase-like Activity of Papain. RSC Adv. 2019, 9, 16566-16570. [CrossRef]

22. Tagad, C.K.; Dugasani, S.R.; Aiyer, R.; Park, S.; Kulkarni, A.; Sabharwal, S. Green Synthesis of Silver Nanoparticles and Their Application for the Development of Optical Fiber Based Hydrogen Peroxide Sensor. Sens. Actuators B Chem. 2013, 183, 144-149. [CrossRef]

23. Lobnik, A.; Ajlakovi, M. Sol-Gel Based Optical Sensor for Continuous Determination of Dissolved Hydrogen Peroxide. Sens. Actuators B Chem. 2001, 74, 194-199. [CrossRef]

24. Bhatia, P.; Yadav, P.; Gupta, B.D. Surface Plasmon Resonance Based Fiber Optic Hydrogen Peroxide Sensor Using Polymer Embedded Nanoparticles. Sens. Actuators B Chem. 2013, 182, 330-335. [CrossRef] 
25. Jorgenson, R.C.; Yee, S.S. A Fiber-Optic Chemical Sensor Based on Surface Plasmon Resonance. Sensors Actuators B. Chem. 1993, 12, 213-220. [CrossRef]

26. Elosua, C.; Arregui, F.J.; Del Villar, I.; Ruiz-Zamarreño, C.; Corres, J.M.; Bariain, C.; Goicoechea, J.; Hernaez, M.; Rivero, P.J.; Socorro, A.B.; et al. Micro and Nanostructured Materials for the Development of Optical Fibre Sensors. Sensors 2017, 17, 2132. [CrossRef] [PubMed]

27. Bao, X.; Chen, L. Recent Progress in Distributed Fiber Optic Sensors. Sensors 2012, 12, 8601-8639. [CrossRef]

28. Sharma, S.; Kumari, R.; Varshney, S.K.; Lahiri, B. Optical Biosensing with Electromagnetic Nanostructures. Rev. Phys. 2020, 5, 100044. [CrossRef]

29. Liz-marza, L.M. In V Ited Feature Article. Langmuir 2006, 22, 32-41.

30. Schopf, C.; Martín, A.; Iacopino, D. Plasmonic Detection of Mercury via Amalgam Formation on Surface-Immobilized Single Au Nanorods. Sci. Technol. Adv. Mater. 2017, 18, 60-67. [CrossRef]

31. Schopf, C.; Martín, A.; Schmidt, M.; Iacopino, D. Investigation of Au-Hg Amalgam Formation on Substrate-Immobilized Individual Au Nanorods. J. Mater. Chem. C 2015, 3, 8865-8872. [CrossRef]

32. Goicoechea, J.; Rivero, P.J.; Sada, S.; Arregui, F.J. Self-Referenced Optical Fiber Sensor for Hydrogen Peroxide Detection Based on LSPR of Metallic Nanoparticles in Layer-by-Layer Films. Sensors 2019, 19, 3872. [CrossRef] [PubMed]

33. Rivero, P.J.; Goicoechea, J.; Arregui, F.J. Layer-by-Layer Nano-Assembly: A Powerful Tool for Optical Fiber Sensing Applications. Sensors 2019, 19, 683. [CrossRef] [PubMed]

34. Decher, G. Fuzzy Nanoassemblies: Toward Layered Polymeric Multicomposites. Science 1997, 277, 1232-1237. [CrossRef]

35. Rivero, P.J.; Goicoechea, J.; Urrutia, A.; Matias, I.R.; Arregui, F.J. Multicolor Layer-by-Layer Films Using Weak Polyelectrolyte Assisted Synthesis of Silver Nanoparticles. Nanoscale Res. Lett. 2013, 8, 438. [CrossRef]

36. Decher, G.; Eckle, M.; Schmitt, J.; Struth, B. Layer-by-Layer Assembled Multicomposite Films. Curr. Opin. Colloid Interface Sci. 1998, 3, 32-39. [CrossRef]

37. Shiratori, S.S.; Rubner, M.F. PH-Dependent Thickness Behavior of Sequentially Adsorbed Layers of Weak Polyelectrolytes Macromolecules 2000, 33, 301, 4213-4219. [CrossRef]

38. Martínez-Hernández, M.E.; Sandua, X.; Rivero, P.J.; Goicoechea, J.; Arregui, F.J. An Optical Fiber Sensor for $\mathrm{Hg}^{2+}$ Detection Based on the LSPR of Silver and Gold Nanoparticles Embedded in a Polymeric Matrix as an Effective Sensing Material. Chem. Proc. 2021, 5, 73. [CrossRef]

39. Rivero, P.J.; Goicoechea, J.; Matias, I.R.; Arregui, F.J. A Comparative Study of Two Different Approaches for the Incorporation of Silver Nanoparticles into Layer-by-Layer Films. Nanoscale Res. Lett. 2014, 9, 301. [CrossRef]

40. Rivero, P.J.; Goicoechea, J.; Hernaez, M.; Socorro, A.B.; Matias, I.R.; Arregui, F.J. Optical Fiber Resonance-Based PH Sensors Using Gold Nanoparticles into Polymeric Layer-by-Layer Coatings. Microsyst. Technol. 2016, 22, 1821-1829. [CrossRef]

41. Rivero, P.J.; Urrutia, A.; Goicoechea, J.; Arregui, F.J. Optical Fiber Humidity Sensors Based on Localized Surface Plasmon Resonance (LSPR) and Lossy-Mode Resonance (LMR) in Overlays Loaded with Silver Nanoparticles. Sens. Actuators B. Chem. 2012, 173, 244-249. [CrossRef]

42. Sanchez, P.; Zamarreño, C.R.; Hernaez, M.; Matias, I.R.; Arregui, F.J. Optical fiber refractometers based on Lossy Mode Resonances by means of $\mathrm{SnO}_{2}$ sputtered coatings. Sens. Actuators B Chem. 2014, 202, 154-159. [CrossRef]

43. Zhong, X.; Ma, L.; Yin, G.; Gan, M.; Wei, Y. $\mathrm{Hg}^{2+}$ Optical Fiber Sensor Based on LSPR with PDDA-Templated AuNPs and CS/PAA Bilayers. Appl. Sci. 2020, 10, 4845. [CrossRef]

44. Endo, T.; Yanagida, Y.; Hatsuzawa, T. Quantitative Determination of Hydrogen Peroxide Using Polymer Coated Ag Nanoparticles. Meas. J. Int. Meas. Confed. 2008, 41, 1045-1053. [CrossRef]

45. Tsanova, P.; Donkova, B.; Karadjova, I.; Dushkin, C. Synthesis of Starch-Stabilized Silver Nanoparticles and Their Application as a Surface Plasmon Resonance-Based Sensor of Hydrogen Peroxide. Colloids Surfaces A Physicochem. Eng. Asp. 2011, 382, 203-210. [CrossRef] 